\title{
Azidophosphonium salt-directed chemoselective synthesis of $(E) /(Z)$-cinnamyl-1H-triazoles and regiospecific access to bromomethylcoumarins from Morita-Baylis-Hillman adducts
}

\author{
Soundararajan Karthikeyan ${ }^{1}$, Radha Krishnan Shobana ${ }^{1}$, \\ Kamarajapurathu Raju Subimol ${ }^{2}$, J. Helen Ratna Monica ${ }^{1}$ \\ and Ayyanoth Karthik Krishna Kumar ${ }^{*}$
}

\author{
Full Research Paper \\ Address: \\ ${ }^{1}$ Organic \& Material Chemistry Research Laboratory, Department of \\ Chemistry, The American College, Madurai, Tamil Nadu, India and \\ ${ }^{2}$ Department of Chemistry, Fatima College, Madurai, Tamil Nadu, \\ India \\ Email: \\ Ayyanoth Karthik Krishna Kumar* - karthikkumar1265@gmail.com \\ * Corresponding author \\ Keywords: \\ halomethylcoumarin; Morita-Baylis-Hillman adducts; organocatalyst; \\ phosphonium salt; triazolation
}

\author{
Beilstein J. Org. Chem. 2020, 16, 1579-1587. \\ doi:10.3762/bjoc. 16.130 \\ Received: 31 March 2020 \\ Accepted: 22 June 2020 \\ Published: 01 July 2020 \\ Associate Editor: M. Rueping \\ (C) 2020 Karthikeyan et al.; licensee Beilstein-Institut. \\ License and terms: see end of document.
}

\begin{abstract}
The direct transformation of Morita-Baylis-Hillman (MBH) adducts into molecules of interest is a crucial process wherein allylic hydroxy-protected or halogenated MBH adducts are commonly preferred. Herein, we report an azidophosphonium salt (AzPS)-catalysed straight forward protocol for synthesising structurally demanding $(E) /(Z)$-cinnamyl-1H-1,2,3-triazoles and halomethylcoumarins from $\mathrm{MBH}$ adducts. The novel methodology, efficient catalyst, and direct utilization of $\mathrm{MBH}$ adducts under mild reaction conditions qualify the reported procedures as powerful synthetic tools.
\end{abstract}

\section{Introduction}

The presence of versatile functional groups in close proximity classifies Morita-Baylis-Hillman adducts as privileged key scaffolds for synthetic organic chemists. Accordingly, $\mathrm{MBH}$ adducts have been explored as strategic intermediates for the synthesis of interesting molecules, such as carbamates of unsaturated $\beta$-amino acids [1], $\beta$-phenylsylfenyl- $\alpha$-cyanohydrocinnamaldhydes [2], 2-alkylcarbonyl-1-indanols [3], dihydropyrazoles [4], tetrahydroacridines [5], $\gamma$-lactams [6], quinolin-5-ones [7], spirobisglutarimides [8], indolizines [9], and spiro carbo- cyclic frameworks [10]. However, most of the reported synthetic transformations utilize either allylic hydroxy-protected or allyl halide-substituted MBH adducts [11-23].

Among the known synthetic transformations using functionalized MBH adducts, cycloaddition reactions are challenging and attractive for synthetic organic chemists. In this context, acetate-functionalized Morita-Baylis-Hillman adducts have been extensively utilized over other precursors. For example, 
heterocycles such as, pyrroles (e.g., IV) [24], keto pyrroles (e.g., V) [25], pyridines (e.g., VI) [26], pyrrolotriazoles (e.g., VII) [27], and triazolobenzoxazonines (e.g., VIII) [28] result from $\mathrm{MBH}$ acetates (Scheme 1). From these synthetic elaborations, three successive steps are universally utilized: (i) acetylation, (ii) azidation, and (iii) cycloaddition to produce IV-VIII In spite of the broad scope and synthetic utility, it is evident that the multistep synthetic methodology is the only existing module for cycloaddition reactions.

Our research group is focused on developing one-pot synthetic transformations for complex molecules [29-31]. Two individual research groups have reported the multistep pathway to access the cinnamyl-1H-1,2,3-triazole derivatives IX from acetates of MBH adducts (Scheme 2) [32,33]. The other preferable moiety for triazole transformations is the allyl halide of $\mathrm{MBH}$ adducts, however, the vicinity of its $(E)$ - and $(Z)$ isomers restricts their use as a favourable starting moiety [34]. After a careful bibliographic investigation, it became evident that there were no one-pot protocols for direct transformations of MBH adducts to cinnamyl triazoles. The outcome of developing a one-pot synthetic strategy will be worthwhile for pharmacologically important triazoles, such as isavuconazole, tazobactam, and ravuconazole [35].

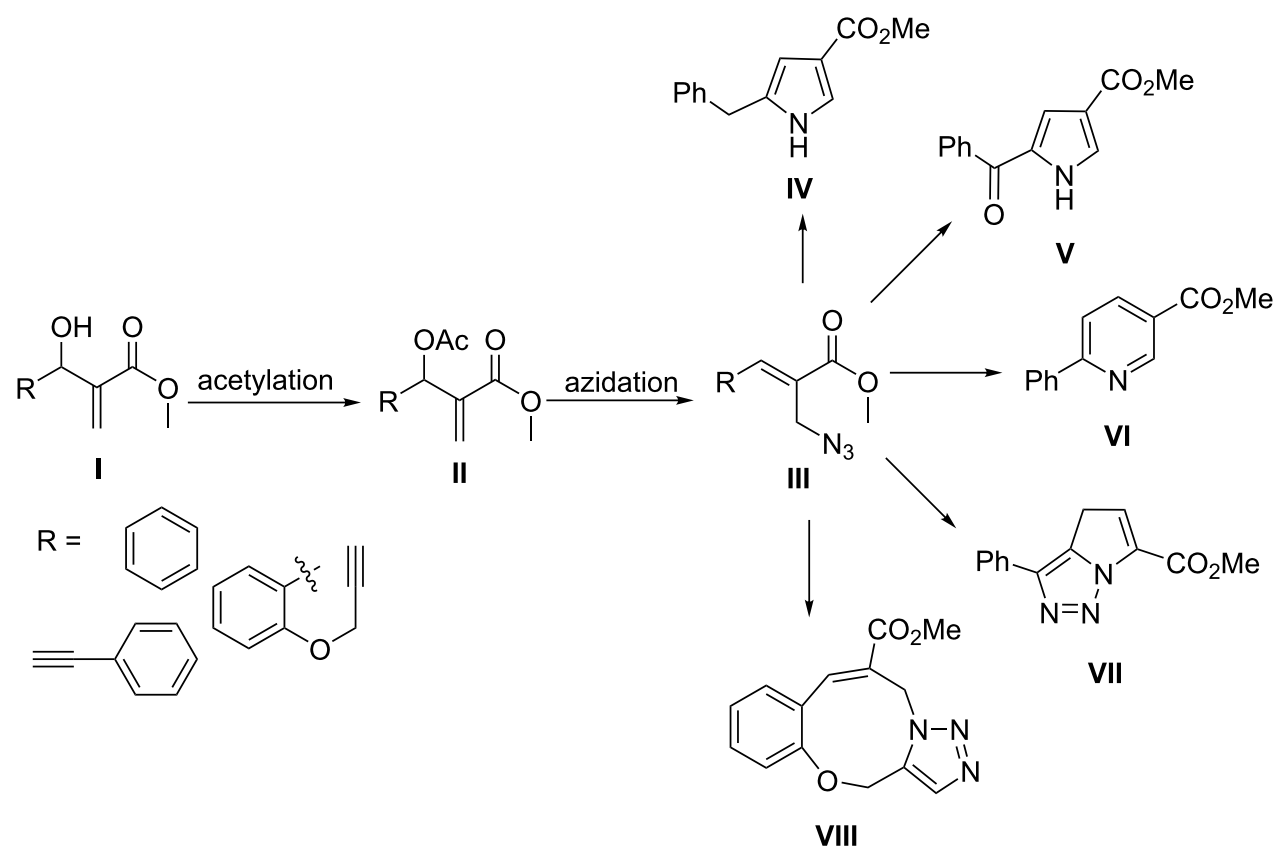

Scheme 1: Literature-reported cycloaddition reactions of MBH acetates involving azides and alkynes [24-28]

a)

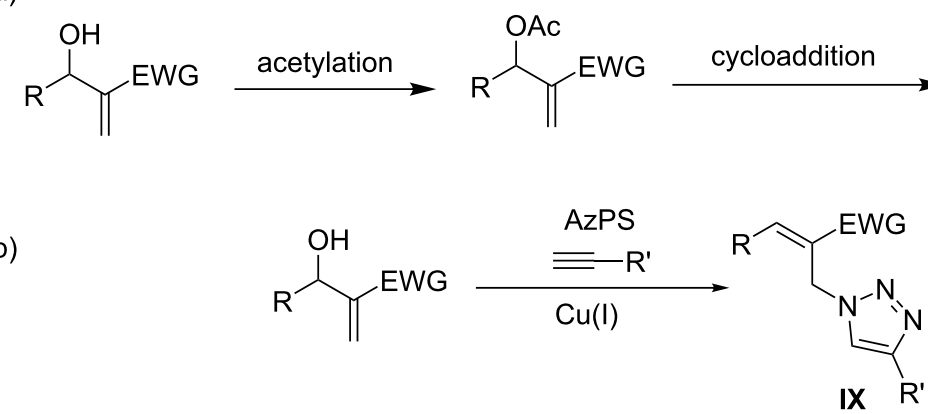




\section{Results and Discussion}

Initially, phosphonium salts were barely utilised or exploited in synthetic transformations. Later, in 2014, several organic transformations employed quaternary phosphonium salts as favourable catalysts [36]. Their synthetic utility was not only confined to catalysis, but they were also used as intermediates for the synthesis of $1 \mathrm{H}$-indazoles [37], as promoters for stereoselective rearrangements [38], and as temporary protectors of $\mathrm{O}, \mathrm{P}$-acetals [39], which branded them as promising motifs. The above reports and the Lewis acid character of quaternary phosphonium salts (QPS) [40-48] qualifies them as reliable catalysts for the proposed methodology. The most elaborate process in the proposed methodology is the protection and elimination of the allylic hydroxy group. We believe that this crucial strategy could be primarily resolved by a quaternary phosphonium salt. After the initial screening of various quaternary phosphonium salts, the azidophosphonium salt $\left[\mathrm{Ph}_{3} \mathrm{P}^{+} \mathrm{CBr}_{3}\right] \mathrm{N}_{3}^{-}$, reported by Blanco and co-workers, was opted to accomplish our goal [49-51]. The AzPS surprisingly synchronised with the functional and structural requirements of the proposed work. The azidophosphonium salt was generated and purified according to a modified literature procedure [49].

The one-pot model reaction was investigated using the $\mathrm{MBH}$ adduct 1a (1 equiv) and propargyl alcohol (2a, 1.2 equiv) in presence of the AzPS $\left[\mathrm{Ph}_{3} \mathrm{P}^{+} \mathrm{CBr}_{3}\right] \mathrm{N}_{3}^{-}$(see Supporting Infor- mation File 1 for the substituent patterns of the compounds $\mathbf{1 a}-\mathbf{o})$. In this precedent reaction, the adduct 1a and propargyl alcohol (2a) in THF were treated with the AzPS (1 equiv) and $\mathrm{CuI}(3 \mathrm{~mol} \%)$ at room temperature. To our expectations, the reaction afforded the $(E)$-cinnamyl-1H-1,2,3-triazole in a low yield of $24 \%$ (Table 1, entry 1). Thereby, we anticipated that an increase in the proportion of the AzPS would substantially increase the yield of 3a (Table 1, entries 2 and 3), but unexpectedly, the reaction demonstrated an unsatisfactory yield. Thereafter, on attempting the reaction with an improved ratio of $\mathrm{CuI}$ (5 mol \%) and AzPS ( 2 equiv), the expected product 3a was obtained in a moderate yield ( $71 \%$, Table 1 , entry 4$)$. However, a further increase in the AzPS ascertained a gradual decrease in the yield of $\mathbf{3 a}$ (Table 1, entries 5 and 6). The outcome of this analysis might have been due to the formation of large amounts of the byproduct triphenylphosphine oxide, which impeded the purification process and decreased the yield of 3a. Alternative $\mathrm{Cu}(\mathrm{I})$ catalysts, $\mathrm{CuCl}$ and $\mathrm{CuBr}$, were also used at $5 \mathrm{~mol} \%$ with the AzPS ( 2 equiv), however, the combination showed no potential increase in the yield of $\mathbf{3 a}$ (Table 1, entries 7 and 8). Comprehensive investigations on the proposed methodology revealed 2 equiv of the AzPS and $5 \mathrm{~mol} \%$ of $\mathrm{CuI}$ as the optimized catalytic combination. Further, the optimized reaction was screened in presence of various solvents (Table 1, entries 9-13), and the outcome revealed acetonitrile as the most preferable solvent, yielding $\mathbf{3 a}$ in $83 \%$ yield (Table 1, entry 11 ). Inter-

Table 1: Optimization of the triazolation of the MBH adduct 1a

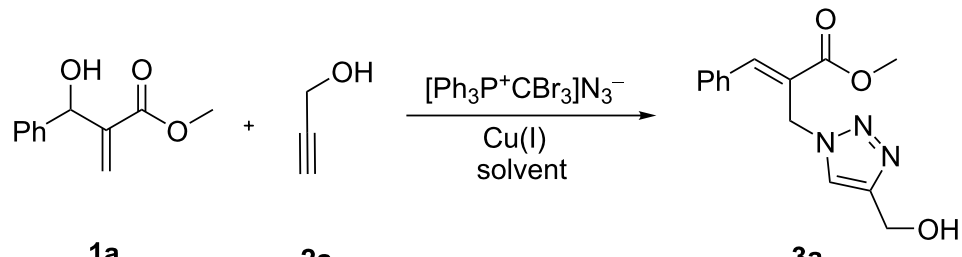

$1 \mathrm{a}$

$2 a$

$3 a$

\begin{tabular}{|c|c|c|c|c|}
\hline entry & equiv of AzPS & $\mathrm{Cu}(\mathrm{I})$ salt $(\mathrm{mol} \%)$ & solvent & yield $(\%)$ \\
\hline 1 & 1 & Cul (3) & THF & 24 \\
\hline 2 & 1.5 & Cul (3) & THF & 33 \\
\hline 3 & 2 & Cul (3) & THF & 42 \\
\hline 4 & 2 & Cul (5) & THF & 71 \\
\hline 5 & 3 & Cul (5) & THF & 45 \\
\hline 6 & 4 & Cul (5) & THF & 36 \\
\hline 7 & 2 & $\mathrm{CuCl}(5)$ & THF & 47 \\
\hline 8 & 2 & CuBr (5) & THF & 54 \\
\hline 9 & 2 & Cul (5) & EtOAc & 66 \\
\hline 10 & 2 & Cul (5) & acetone & 69 \\
\hline 11 & 2 & Cul (5) & $\mathrm{CH}_{3} \mathrm{CN}$ & 83 \\
\hline 12 & 2 & Cul (5) & DMF & 64 \\
\hline 13 & 2 & Cul (5) & DMSO & 69 \\
\hline
\end{tabular}


estingly, the dilution of the reaction mixture did not alter the efficiency of this reaction.

The substrate scope of the optimized reaction and its limitations were further extended to structurally distinct $\mathrm{MBH}$ adducts (Scheme 3 ). The MBH adducts derived from methoxy and ethoxy acrylate stereochemically afforded the $(E)$ cinnamyl-1,4-disubstituted 1,2,3-triazole derivatives $\mathbf{3 a}-\mathbf{d} / \mathbf{g}-\mathbf{k} /$ $\mathbf{m}-\mathbf{q}$ in a yield of $70-88 \%$. Distinctively, the cyano acrylatesubstituted $\mathrm{MBH}$ adduct stereoselectively afforded the $(Z)$ -

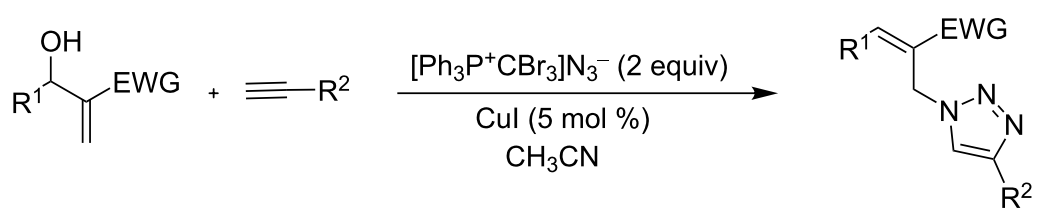<smiles>COC(=O)/C(=C/c1ccccc1)Cn1cc(CO)nn1</smiles>

3a $(83 \%)$<smiles>COC(=O)/C(=C/c1ccccc1)Cn1cc(-c2ccccc2)nn1</smiles>

3b $(88 \%)$<smiles>CCOC(=O)/C(=C/c1ccccc1)Cn1cc(CO)nn1</smiles>

3c $(80 \%)$<smiles>CCOC(=O)/C(=C/c1ccccc1)Cn1cc(-c2ccccc2)nn1</smiles>

3d (82\%)<smiles>N#C/C(=C\c1ccccc1)Cn1cc(CO)nn1</smiles>

3 e $(90 \%)$<smiles>N#C/C(=C\c1ccccc1)Cn1cc(-c2ccccc2)nn1</smiles>

$3 f(92 \%)$<smiles>COC(=O)/C(=C/c1ccc(Cl)cc1)Cn1cc(CO)nn1</smiles>

3g $(72 \%)$<smiles>COC(=O)/C(=C/c1ccc(Cl)cc1)Cn1cc(-c2ccccc2)nn1</smiles>

3h (78\%)<smiles>COC(=O)/C(=C/c1ccc(Br)cc1)Cn1cc(CO)nn1</smiles>

$3 \mathbf{i}(80 \%)$<smiles>COC(=O)/C(=C/c1ccc(Br)cc1)Cn1cc(-c2ccccc2)nn1</smiles>

3j (84\%)<smiles>CCOC(=O)/C(=C/c1ccc(Br)cc1)Cn1cc(CO)nn1</smiles>

3k $(78 \%)$<smiles>N#C/C(=C\c1cccc(Br)c1)Cn1cc(CO)nn1</smiles>

3I (82\%)<smiles>COC(=O)/C(=C/c1ccc([N+](=O)[O-])cc1)Cn1cc(CO)nn1</smiles>

$3 \mathrm{~m}(87 \%)$<smiles>COC(=O)/C(=C/c1ccco1)Cn1cc(-c2ccccc2)nn1</smiles>

3n (80\%)<smiles>CCOC(=O)/C(=C/c1ccco1)Cn1cc(-c2ccccc2)nn1</smiles>

30 $(76 \%)$<smiles>COC(=O)/C(=C/c1cccs1)Cn1cc(-c2ccccc2)nn1</smiles>

$3 p(75 \%)$<smiles>CCOC(=O)/C(=C/c1cccs1)Cn1cc(-c2ccccc2)nn1</smiles>

3q $(70 \%)$

Scheme 3: Scope of the one-pot cascade reaction of the unprotected Morita-Baylis-Hillman adducts 3a-q 
cinnamyl-1,4-disubstituted 1,2,3-triazole derivatives $\mathbf{3 e} / \mathbf{f} / \mathbf{l}$ in a yield of $82-92 \%$. Irrespective of the acetylene moiety, the MBH adducts derived from acrylonitrile comparatively afforded cinnamyl-1,4-disubstituted 1,2,3-triazoles at an improved yield compared to that of the methyl and ethyl counterparts. Notably, the MBH adducts derived from the para-bromo-, para-chloro-, and para-nitrobenzaldehydes favourably assisted the formation of the corresponding $(E)$-cinnamyl-1,4-disubstituted 1,2,3-triazole derivatives $\mathbf{3 g}-\mathbf{m}$ in a yield of $72-87 \%$. Alternatively, the ortho- and meta-substituted aryl-MBH adducts were incompatible with the optimized reaction conditions, and this was presumably due to the apparent steric hindrance. Similarly, the MBH adducts derived from aliphatic aldehydes, salicylaldehydes, and methyl- or methoxy-substituted benzaldehydes were also inert under the optimized reaction conditions. Therefore, it is evident that the electronic variation of the substituents on the aromatic moiety of the $\mathrm{MBH}$ adducts played a crucial role in determining the outcome of the optimized reactions. We further extended the scope of this transformation to five-membered heterocyclic MBH adducts. To our delight, except pyrroles, the proposed methodology was amenable to $\mathrm{MBH}$ adducts of furan and thiophene (3n-q, 70-80\%).

The mechanistic pathway for the triazolation proceeded via a nucleophilic attack on the AzPS by the allylic alcohol of the MBH adduct Ia. Subsequently, the azide ion undergoes a nucleophilic attack on the allylic carbon atom of the oxyphosphonium intermediate IIa and generates the 2-azidoalkene IIIa. Interestingly, the consecutive nucleophilic attack by the azido ion smoothly initiates the allylic rearrangement and thereby facilitates the removal of the crucial phosphonium oxide. The outcome of this process is the structurally relevant azido moiety IIIa, which then undergoes a 1,3-dipolar cycloaddition with the copper acetylide IVa to furnish the 1,4-disubstituted 1,2,3-triazoles Va (Figure 1).

At this stage, we sought to analyse the outcome of the proposed reaction following a sequential addition of the reagents utilised for the synthesis of AzPS. Therefore, a preliminary investigation was attempted using the MBH adduct 1a (1 equiv) and propargyl alcohol (2a,1.2 equiv) in the presence of $\mathrm{CuI}$ (5 mol \%), triphenylphosphine (1 equiv), bromomethane (1.1 equiv), and sodium azide ( 2 equiv). Unexpectedly, the reaction yielded $(Z)$-methyl-2-(bromomethyl)-3-phenylacrylate $(58 \%)$ over the expected triazole. Similarly, the MBH adduct derived from furan, $\mathbf{1 i}$, and phenylacetylene (2b) also yielded (Z)-methyl 2-(bromomethyl)-3-(furan-2-yl)acrylate (42\%) rather than the expected triazole (Scheme 4). Thereby, it was clearly evident that the addition of the individual reagents prevented the formation of complicated triazoles.

Interestingly, the MBH adducts derived from salicylaldehydes were inert to triazolations, surprisingly affords bromomethylcoumarin in the presence of AzPS and $\mathrm{HBr}$. The reaction was optimized using salicylaldehyde (1 equiv) in the presence of AzPS ( 2 equiv) and $\mathrm{HBr}$ (2.0 equiv). The reaction afforded 6-(bromomethyl)coumarin (4a) in a yield of 78\% (Table 2, entry 3 ). The synthetic utility of the reaction was further extended to ortho-vanillin and para-bromobenzaldehyde to afford the corresponding halomethylcoumarins $(\mathbf{4 b} / \mathbf{c})$. However, this regiospecific transformation was restricted only to the $\mathrm{MBH}$ adducts derived from salicyladehydes and tert-butyl acrylate

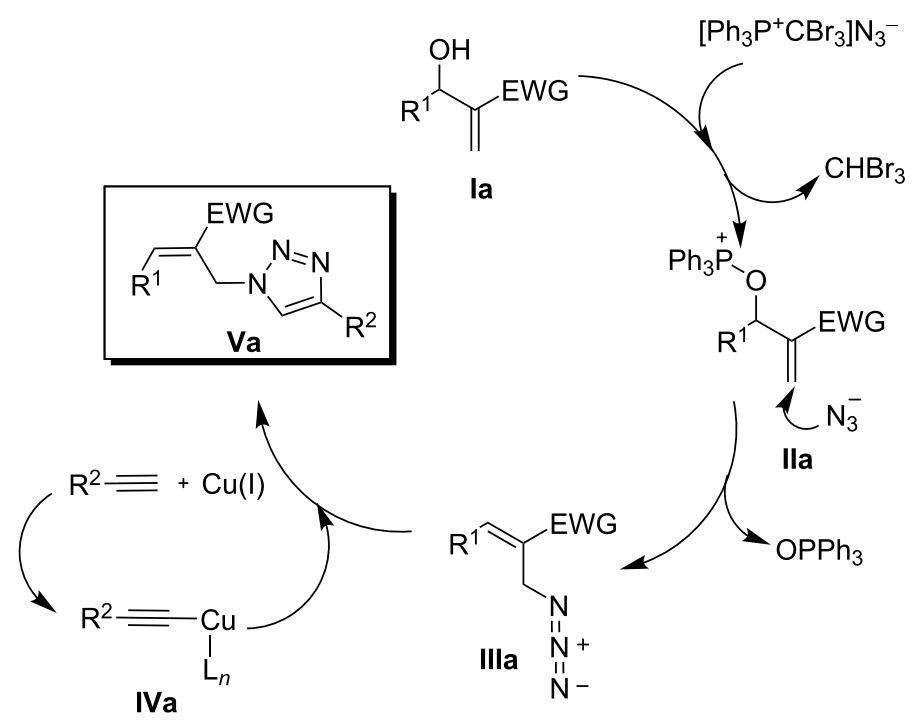

Figure 1: Proposed mechanism for the synthesis of 1,4-disubstituted triazoles. 
<smiles>C=C(C(=O)OC)C(O)c1ccccc1</smiles>

$1 \mathrm{a}$<smiles>C#CCO</smiles>

$2 a$
$\mathrm{PPh}_{3}$ (1 equiv), $\mathrm{CBr}_{4}$ (1.1 equiv),

$\mathrm{NaN}_{3}$ (2 equiv), Cul (5 mol \%), $\mathrm{CH}_{3} \mathrm{CN}$

$\mathrm{PPh}_{3}$ (1 equiv), $\mathrm{CBr}_{4}$ (1.1 equiv),

$\mathrm{NaN}_{3}$ (2 equiv), Cul (5 mol \%), $\mathrm{CH}_{3} \mathrm{CN}$<smiles>COC(=O)/C(=C/c1ccccc1)CBr</smiles>

observed

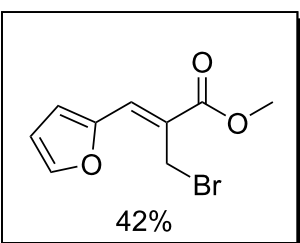

observed<smiles>COC(=O)/C(=C/c1ccccc1)Cn1cc(CO)nn1</smiles>

expected<smiles>COC(=O)/C(=C/c1ccco1)Cn1cc(CO)nn1</smiles>

Scheme 4: Comparative analysis of the sequential one-pot reaction.

Table 2: Optimization of the reaction conditions for 3-(bromomethyl)coumarins from MBH adducts.<smiles>[R]c1cc([R1])c(O)c(C(O)C(=C)C(=O)OC(C)(C)C)c1</smiles>

$1 \mathrm{~m}-\mathrm{o}$<smiles>[R2]c1cc([R1])c2oc(=O)c(CBr)cc2c1</smiles>

4a-c<smiles>O=c1oc2ccccc2cc1CBr</smiles>

$4 a$<smiles>COc1cccc2cc(CBr)c(=O)oc12</smiles>

4b<smiles>O=c1oc2ccc(Br)cc2cc1CBr</smiles>

$4 c$

\begin{tabular}{ccccc}
\hline entry & equiv of AzPS & equiv of $\mathrm{HBr}$ & solvent & yield $\mathbf{4 a}(\%)$ \\
\hline 1 & 2 & - & $\mathrm{CH}_{3} \mathrm{CN}$ & - \\
2 & 2 & 1 & $\mathrm{CH}_{3} \mathrm{CN}$ & 33 \\
3 & 2 & 2 & $\mathrm{CH}_{3} \mathrm{CN}$ & 78 \\
4 & 2 & 3 & $\mathrm{CH}_{3} \mathrm{CN}$ & 62 \\
5 & 2 & 4 & $\mathrm{CH}_{3} \mathrm{CN}$ & 31 \\
6 & 3 & 2 & $\mathrm{CH}_{3} \mathrm{CN}$ & 65 \\
7 & 4 & 2 & $\mathrm{CH}_{3} \mathrm{CN}$ & 57
\end{tabular}

[52,53]. Among the reported methodologies on synthesis of halomethylcoumarins [54,55], the present methodology was attractive due to its good yield and the simple reaction conditions.

As shown in Figure 2, the mechanistic pathway for $\mathbf{4 a}-\mathbf{c}$ progressed via treating the MBH adduct (1m) with AzPS and $\mathrm{HBr}$. The outcome of this process was the phosphonium-protected MBH moiety Ib and hydrazoic acid. The counter ion bromine facilitated the nucleophilic attack at the vinylic centre of Ib and the spontaneous removal of triphenylphosphine oxide to yield IIb. A consecutive intramolecular nucleophilic attack of the hydroxy moiety at the carbonyl carbon of IIIb further drove the cyclisation to afford the bromomethylcoumarin $\mathbf{4 a}$.

\section{Conclusion}

In summary, we reported the first protocol on the quaternary phosphonium salt-mediated direct synthesis of cinnamyltria- 


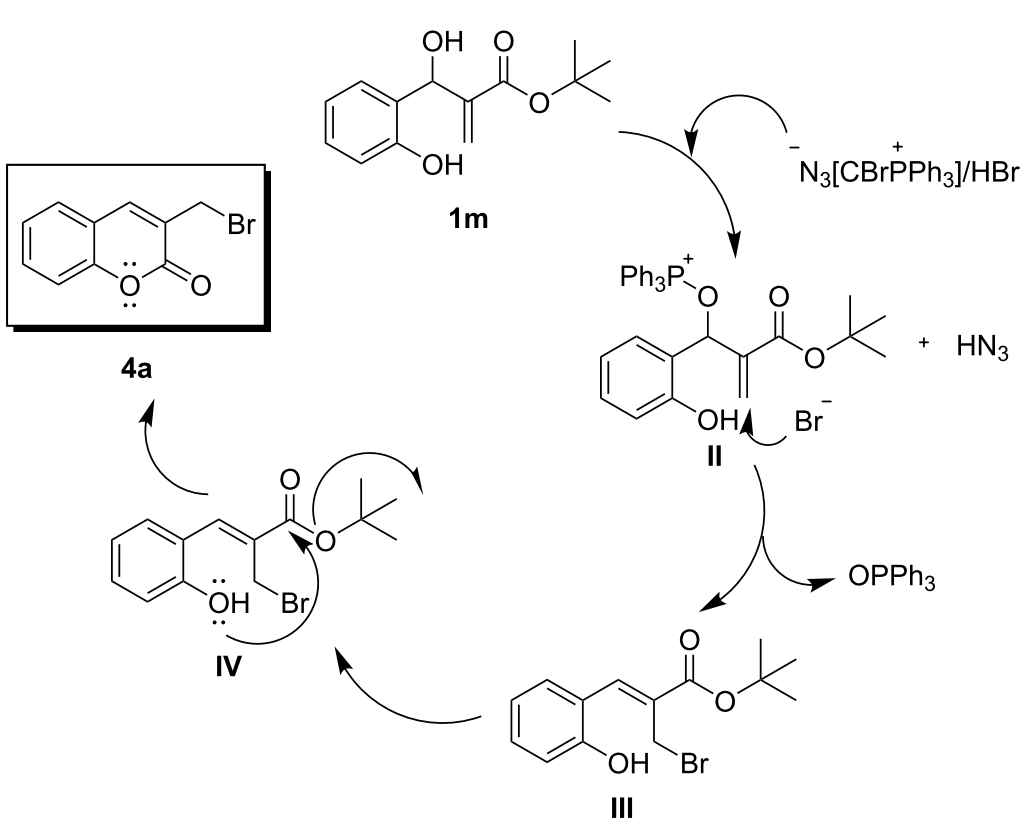

Figure 2: Proposed mechanism for the synthesis of 3-(bromomethyl)coumarins.

zoles and 3-(bromomethyl)coumarins from Morita-Baylis-Hillman adducts. In contrast to the contending reports on the synthesis of 1,2,3-triazoles and halomethylcoumarins from $\mathrm{MBH}$ adducts, our studies report moderate reaction conditions with an improved yield. The above investigation provides a useful synthetic tool for synthetic organic chemists. The synthesis of biologically important triazoles using the reported methodology is underway in our laboratory.

\section{Experimental}

\section{General information}

Chemicals were purchased from Sigma-Aldrich, Spectrochem (P) Ltd., Central Drug House (P) Ltd., and Rankem, India. All chemicals were used without further purification. The solvents were purified using standard procedures. ${ }^{1} \mathrm{H}$ and ${ }^{13} \mathrm{C}$ NMR spectra were recorded on a Bruker Avance $300 \mathrm{MHz}$ spectrometer using $\mathrm{CDCl}_{3}$ and DMSO- $d_{6}$ as the solvent. Tetramethylsilane (TMS) was used as an internal standard. Chemical shifts are given in $\delta$ relative to TMS. High-resolution mass spectra were recorded on an Agilent Technologies 6540 UHD accurate mass Q-TOF LC-MS spectrometer. Melting points are uncorrected. The compounds were purified using column chromatography on silica gel (100-200 mesh) using hexane/ethyl acetate and chloroform/methanol as eluent.

\section{Typical procedure for quaternary phosphonium salts}

As described in [49]. Typically, triphenylphosphine, bromomethane, and sodium azide at a molar ratio of 1.1:1.1:5 were utilized for synthesising the quaternary phosphonium salt. Initially, triphenylphosphine and sodium azide were stirred at $0{ }^{\circ} \mathrm{C}$ in dimethylformamide $(5 \mathrm{~mL})$ for 30 minutes. To the mixture, bromomethane in DMF was added slowly to avoid a sudden increase in temperature. The reaction was slowly warmed to room temperature and stirred for another 30 minutes. Finally, the reaction was quenched by the addition of diethyl ether. The filtration of insoluble inorganic salts resulted in a transparent liquid, which, upon concentration by evaporation, provided a crude oily residue. The residue was dissolved in ethyl acetate, washed with brine, and dried over sodium sulphate to yield a clear oily residue of the quaternary phosphonium salt.

\section{Typical procedure for 1a-0}

As described in [52]. A mixture of benzaldehyde (1.1 g, $1.14 \mathrm{~mL}, 0.01 \mathrm{~mol})$, methyl acrylate $(2.05 \mathrm{~g}, 2.15 \mathrm{~mL}$, $0.023 \mathrm{~mol})$ and DABCO (0.87 g, $0.0077 \mathrm{~mol})$ in chloroform $(5 \mathrm{~mL})$ was stirred at room temperature for $7 \mathrm{~d}$. The reaction mixture was quenched with $10 \%$ aqueous hydrochloric acid $(50 \mathrm{~mL})$ and washed repeatedly with water. The chloroform extract was then dried, concentrated, and purified by column chromatography (hexane/EtOAc 8:2, v/v) to afford 1a as colourless oil (1.64 gm, 85\%).

\section{Typical procedure for $3 a-q$}

A solution of AzPS (2 equiv) in acetonitrile $(5 \mathrm{~mL})$ was added to a solution of the Morita-Baylis-Hillman adduct 1a (1 equiv) in acetonitrile $(3 \mathrm{~mL})$. The reaction mixture was then stirred for 
an hour, and 1.2 equiv of propargyl alcohol (2a) and $\mathrm{CuI}$ ( $5 \mathrm{~mol} \%$ ) were added. The reaction mixture was stirred for another 4 hours, followed by TLC analysis. After the completion of the reaction, the solution was concentrated, diluted, and extracted with EtOAc. The combined extracts were washed with brine, filtered through a celite bed, and dried over anhydrous $\mathrm{Na}_{2} \mathrm{SO}_{4}$. Thereafter, the solvent was removed, and the isolated crude oily product was purified over silica gel $\left(\mathrm{CHCl}_{3} /\right.$ $\mathrm{MeOH}$ ) to obtain $\mathbf{3 a}$ as a white solid.

\section{Typical procedure for $\mathbf{4 a - c}$}

To a mixture of the Morita-Baylis-Hillman adduct (1 equiv) and AzPS ( 2 equiv) in acetonitrile ( $3 \mathrm{~mL}$ ), $\mathrm{HBr}$ ( 2 equiv) was added carefully at room temperature. After 2 hours, the reaction mixture was quenched with water $(20 \mathrm{~mL})$ and then extracted with ethyl acetate. The organic layer was washed with brine and dried over anhydrous $\mathrm{MgSO}_{4}$. The removal of the solvent in vacuo afforded the crude product, which was purified over silica gel (using hexane/EtOAc) to acquire $\mathbf{4 a}$ as colorless crystals.

\section{Supporting Information}

\section{Supporting Information File 1}

Compound characterization data and NMR spectra.

[https://www.beilstein-journals.org/bjoc/content/

supplementary/1860-5397-16-130-S1.pdf]

\section{Acknowledgements}

The authors thank the institute for the necessary infrastructure.

\section{Funding}

The authors thank the DST-SERB Government of India (file no: YSS/2014/000358) for the financial support.

\section{ORCID ${ }^{\circledR} \mathrm{iDs}$}

Ayyanoth Karthik Krishna Kumar - https://orcid.org/0000-0002-2444-7734

\section{Preprint}

A non-peer-reviewed version of this article has been previously published as a preprint doi:10.3762/bxiv.2020.38.v1

\section{References}

1. Mamaghani, M.; Badrian, A. Tetrahedron Lett. 2004, 45, 1547-1550. doi:10.1016/j.tetlet.2003.12.046

2. Yadav, L. D. S.; Srivastava, V. P.; Patel, R. Tetrahedron Lett. 2008, 49, 3142-3146. doi:10.1016/j.tetlet.2008.03.016

3. Tu, S.; Xu, L.-H.; Yu, C.-R. Synth. Commun. 2008, 38, 2662-2671. doi:10.1080/00397910601038731
4. Gowrisankar, S.; Kim, K.-H.; Kim, J.-N. Bull. Korean Chem. Soc. 2008, 29, 2537-2539. doi:10.5012/bkcs.2008.29.12.2537

5. Basavaiah, D.; Rao, J. S.; Reddy, R. J. J. Org. Chem. 2004, 69, 7379-7382. doi:10.1021/jo0489871

6. Basavaiah, D.; Srivardhana Rao, J. Tetrahedron Lett. 2004, 45, 1621-1625. doi:10.1016/j.tetlet.2003.12.133

7. Zhong, W.; Lin, F.; Chen, R.; Su, W. Synthesis 2008, 2561-2568. doi:10.1055/s-2008-1078601

8. Basavaiah, D.; Reddy, R. J. Org. Biomol. Chem. 2008, 6, 1034-1039. doi:10.1039/b717843c

9. Basavaiah, D.; Devendar, B.; Lenin, D. V.; Satyanarayana, T. Synlett 2009, 411-416. doi:10.1055/s-0028-1087533

10. Basavaiah, D.; Roy, S. Org. Lett. 2008, 10, 1819-1822. doi:10.1021/ol800424v

11. Weichert, A.; Hoffmann, H. M. R. J. Org. Chem. 1991, 56, 4098-4112. doi:10.1021/jo00013a007

12. Basavaiah, D.; Suguna Hyma, R.; Kumaragurubaran, N. Tetrahedron 2000, 56, 5905-5907. doi:10.1016/s0040-4020(00)00478-6

13. Muthiah, C.; Kumar, K. S.; Vittal, J. J.; Kumara Swamy, K. C. Synlett 2002, 1787-1790. doi:10.1055/s-2002-34899

14. Mase, N.; Wake, S.; Watanabe, Y.; Toru, T. Tetrahedron Lett. 1998, 39, 5553-5556. doi:10.1016/s0040-4039(98)01118-6

15. Drewes, S. E.; Emslie, N. D.; Karodia, N.; Loizou, G. Synth. Commun. 1990, 20, 1437-1443. doi:10.1080/00397919008052859

16. Chung, Y. M.; Gong, J. H.; Kim, T. H.; Kim, J. N. Tetrahedron Lett. 2001, 42, 9023-9026. doi:10.1016/s0040-4039(01)01971-2

17. Chamakh, A.; M'hirsi, M.; Villiéras, J.; Lebreton, J.; Amri, H. Synthesis 2000, 295-299. doi:10.1055/s-2000-6257

18. Ciclosi, M.; Fava, C.; Galeazzi, R.; Orena, M.; Sepulveda-Arques, J. Tetrahedron Lett. 2002, 43, 2199-2202. doi:10.1016/s0040-4039(02)00233-2

19. Wang, M.-X.; Wu, Y. Org. Biomol. Chem. 2003, 1, 535-540. doi:10.1039/b209791e

20. Keck, G. E.; Welch, D. S. Org. Lett. 2002, 4, 3687-3690. doi:10.1021/ol026638s

21. Marino, J. P.; Nguyen, H. N. J. Org. Chem. 2002, 67, 6291-6296. doi:10.1021/jo0110146

22. Ó Dálaigh, C.; Connon, S. J. J. Org. Chem. 2007, 72, 7066-7069. doi:10.1021/jo071223b

23. Liu, J.; Li, Q.; Cao, Z.-M.; Jin, Y.; Lin, J.; Yan, S.-J. J. Org. Chem. 2019, 84, 1797-1807. doi:10.1021/acs.joc.8b02594

24. Reddy, C. R.; Reddy, M. D.; Srikanth, B. Org. Biomol. Chem. 2012, 10 , 4280-4288. doi:10.1039/c2ob25272d

25. Reddy, C. R.; Panda, S. A.; Ramaraju, A. J. Org. Chem. 2017, 82, 944-949. doi:10.1021/acs.joc.6b02468

26. Raji Reddy, C.; Panda, S. A.; Reddy, M. D. Org. Lett. 2015, 17, 896-899. doi:10.1021/ol503752k

27. Park, S. P.; Ahn, S.-H.; Lee, K.-J. Tetrahedron 2010, 66, 3490-3498. doi:10.1016/j.tet.2010.03.017

28. Basavaiah, D.; Reddy, B. S.; Lingam, H. Tetrahedron 2013, 69 , 10060-10067. doi:10.1016/j.tet.2013.09.056

29. Kumar, K. K.; Kumar, R. M.; Subramanian, V.; Das, T. M. Carbohydr. Res. 2010, 345, 2297-2304. doi:10.1016/j.carres.2010.07.037

30. Karthik Kumar, K.; Prabu Seenivasan, S.; Kumar, V.; Mohan Das, T. Carbohydr. Res. 2011, 346, 2084-2090. doi:10.1016/j.carres.2011.06.028

31. Karthik Kumar, K.; Mohan Das, T. Carbohydr. Res. 2011, 346, 728-732. doi:10.1016/j.carres.2011.02.008 
32. Chandrasekhar, S.; Basu, D.; Rambabu, C. Tetrahedron Lett. 2006, 47, 3059-3063. doi:10.1016/j.tetlet.2006.03.037

33. Sreedhar, B.; Reddy, P. S.; Kumar, N. S. Tetrahedron Lett. 2006, 47, 3055-3058. doi:10.1016/j.tetlet.2006.03.007

34. Singh, V.; Hutait, S.; Batra, S. Eur. J. Org. Chem. 2009, 3454-3466. doi:10.1002/ejoc.200900336

35. Dheer, D.; Singh, V.; Shankar, R. Bioorg. Chem. 2017, 71, 30-54. doi:10.1016/j.bioorg.2017.01.010

36. Chen, L.; Xiao, B.-X.; Du, W.; Chen, Y.-C. Org. Lett. 2019, 21, 5733-5736. doi:10.1021/acs.orglett.9b02108

37. Paul, S.; Panda, S.; Manna, D. Tetrahedron Lett. 2014, 55, 2480-2483. doi:10.1016/j.tetlet.2014.03.001

38. Ji, S.-Y.; Sun, Y.-M.; Zhang, H.; Hou, Q.-G.; Zhao, C.-Q. Tetrahedron Lett. 2014, 55, 5742-5744. doi:10.1016/j.tetlet.2014.08.118

39. Yahata, K.; Minami, M.; Watanabe, K.; Fujioka, H. Org. Lett. 2014, 16, 3680-3683. doi:10.1021/ol501463p

40. Werner, T. Adv. Synth. Catal. 2009, 351, 1469-1481. doi:10.1002/adsc.200900211

41. Terada, M.; Kouchi, M. Tetrahedron 2006, 62, 401-409. doi:10.1016/j.tet.2005.09.075

42. Mukaiyama, T.; Kashiwagi, K.; Matsui, S. Chem. Lett. 1989, 18, 1397-1400. doi:10.1246/cl.1989.1397

43. Amurrio, I.; Córdoba, R.; Csákÿ, A. G.; Plumet, J. Tetrahedron 2004, 60, 10521-10524. doi:10.1016/j.tet.2004.07.101

44. Wang, X.; Tian, S.-K. Tetrahedron Lett. 2007, 48, 6010-6013. doi:10.1016/j.tetlet.2007.06.132

45. Cairns, A. G.; McQuaker, S. J.; Murphy, M. P.; Hartley, R. C. Targeting mitochondria with small molecules: The preparation of MitoB and MitoP as exomarkers of mitochondrial hydrogen peroxide. In Mitochondrial Medicine: Volume II, Manipulating Mitochondrial Function; Weissig, V.; Edeas, M., Eds.; Methods in Molecular Biology, Vol. 1265; Humana Press: Totowa, NJ, USA, 2015; pp 25-50.

doi:10.1007/978-1-4939-2288-8_3

46. Fraser, K. J.; MacFarlane, D. R. Aust. J. Chem. 2009, 62, 309. doi:10.1071/ch08558

47. Enders, D.; Nguyen, T. V. Org. Biomol. Chem. 2012, 10, 5327. doi:10.1039/c2ob25823d

48. Golandaj, A.; Ahmad, A.; Ramjugernath, D. Adv. Synth. Catal. 2017, 359, 3676-3706. doi:10.1002/adsc.201700795

49. Jiménez Blanco, J.; García Fernández, J.; Gadelle, A.; Defaye, J. Carbohydr. Res. 1997, 303, 367-372. doi:10.1016/s0008-6215(97)00176-6

50. Buder, W.; Schmidt, A. Chem. Ber. 1973, 106, 3812-3816. doi:10.1002/cber.19731061207

51. Trippett, S.; Smith, D. J. H. Phosphines and phosphonium salts. In Organophosphorus Chemistry; Trippett, S., Ed.; Royal Society of Chemistry: Cambridge, U.K., 1975; Vol. 6, pp 1-26. doi:10.1039/9781847554291

52. Kaye, P. T.; Musa, M. A. Synthesis 2002, 2701-2706. doi:10.1055/s-2002-35984

53. Kaye, P. T.; Musa, M. A. Synth. Commun. 2003, 33, 1755-1770. doi:10.1081/scc-120018937

54. Hong, W. P.; Lee, K.-J. Synthesis 2005, 33-38. doi:10.1055/s-2004-834916

55. Kaye, P. T.; Musa, M. A.; Nocanda, X. W.; Robinson, R. S. Org. Biomol. Chem. 2003, 1, 1133-1138. doi:10.1039/b300360d

\section{License and Terms}

This is an Open Access article under the terms of the Creative Commons Attribution License (http://creativecommons.org/licenses/by/4.0). Please note that the reuse, redistribution and reproduction in particular requires that the authors and source are credited.

The license is subject to the Beilstein Journal of Organic Chemistry terms and conditions: (https://www.beilstein-journals.org/bjoc)

The definitive version of this article is the electronic one which can be found at: doi:10.3762/bjoc. 16.130 